\title{
脉冲激光全息干涉术在岩石力学 研究中的应用
}

\author{
陈顆郑唗郭继光 ${ }^{*}$ 阎 虹 \\ （国家地震局地球物理研究所，北京）
}

在岩石力学研究中, 经常需要测量岩石各点的变形情况, 即需要观测岩石的变形场. 例如 在和地震预报有关的岩石力学研究中,需要研究地震断层面形成过程中变形场的时空规律. 激 光全息干涉术是进行这种全场性测量的重要手段。 70 年代以来 Spetzler ${ }^{[1]} 、 S o g a{ }^{[2]} 、 S o b o l e v^{[3]}$ 等应用连续激光进行过这种全息干涉测量. 最近我们成功地利用脉冲激光全息炤相进行了干 涉测量.

激光全息干涉术是激光全息照相的最重要的实际应用之一，它可以无接触地测量物体表 面的微小位移或变形, 其精度可达到用来建立全息图的激光器波长的一半 $\left(\mathrm{H}_{\mathrm{e}}-\mathrm{N}_{\mathrm{e}}\right.$ : 波长 $=$ $6328 \AA$, 红宝石: 波长 $=6943 \AA$ ). 脆性岩石直到破裂其变形量仍不大, 例如以 100 毫米长的 济南辉长岩试件进行压缩试验, 至破裂时压缩量仅为 0.1 毫米. 设泊松比 $\nu=0.25$, 则横向 总变形量为 0.025 毫米 $=25$ 微米, 如用千分表来测量,表针仅移动 2.5 格. 但是如果用激光全 息干涉木, 则大约可产生 35 条干涉条纹,精度可提高一个数量级以上,这样就有可能不仅测量 总的位移量, 而且可以测量载荷增量下的位移或变形量. 这对地学问题的研究, 无疑是有重大 意义的.

目前,在岩石力学研究中使用的光源均为连续激光光源, 将它用于岩石试验中存在着一些 技术问题. 一方面在记录一个全息图时,一个必须满足的条件是, 全息装置中的光学元件和被 照物体，在全息干板曝光期间内, 不允许有大于 $1 / 8$ 波长的相对移动（对 $\mathrm{H}_{\mathrm{e}}-\mathrm{N}_{\mathrm{e}}$ 约为 0.91 微米). 当用连续氦氛激光器制做全息图时, 由于受其能量所限, 曝光时间一般在几秒到几十 分钟，因此在此期间内即便是被照物体与全息装置之间有 0.07910 微米/秒的相对运动速度就 已不能得到全息图. 一般地说, 这可以用将被测物与光路放在同一个质量极大的隔振台上来 解决. 但另一方面, 岩石的强度较高, 为了保证足觡大的视场, 岩石试件的尺寸又不能太小. 因 此,一般地说, 用于岩石破裂实验的压机不可能放到光具台上. 此外, 诸如岩石破裂扩展过程 的研究,非谐振波动现象等,是不可能用连续激光器 (如 $\mathrm{H}_{\mathrm{e}}-\mathrm{N}_{\mathrm{c}}$ ) 制做全息图的.

为了克服这个困难，我们采用脉冲激光器做光源. 其出光脉冲宽度为 $20 \times 10^{-9}$ 秒, 在这 样短的时间内就可使全息干板得到足够的嚗光. 在此情况下, 可允许的相对运动速度为 4 米 秒. 这样,甚至象岩石中的冲击波现象,也有可能进行研究. E机机械运动和地基振动的影响 已被有效地克服。

利用脉冲全息干涉法,我们研究了房山大理岩岩石试件 $\left(89.94 \times 45.12 \times 15.00\right.$ 毫米 $\left.{ }^{3}\right)$ 在单

本文 1983 年11月28日收到.

* 北京市光电技术研究所.

第 10 期

科学 通 报

609 
轴压缩下, 破坏过程中位移场的变化过程. 所用的仪器是北京光电技术研究所研制的 JQS-1 型双脉冲激光全息干涉仪,其照相光路见图1, 可测量与岩石试件表面垂直的位移(离面位移), 在单轴压缩实验中, 当压力为 $P_{i}$ 时, 进行第一次嚗光; 当压力增贺 $\Delta P_{i}$, 变为 $P_{i}^{\prime}=P_{i}+\Delta P_{i}$

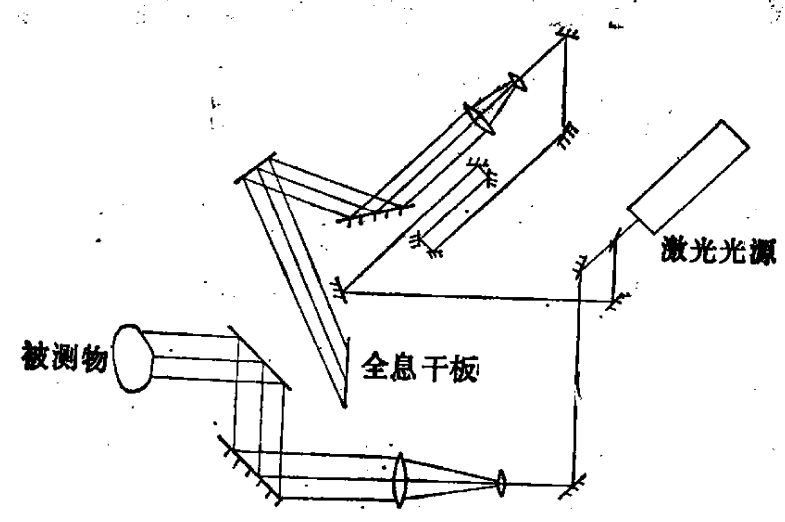

图 1 双脉冲激光干涉仪光路图

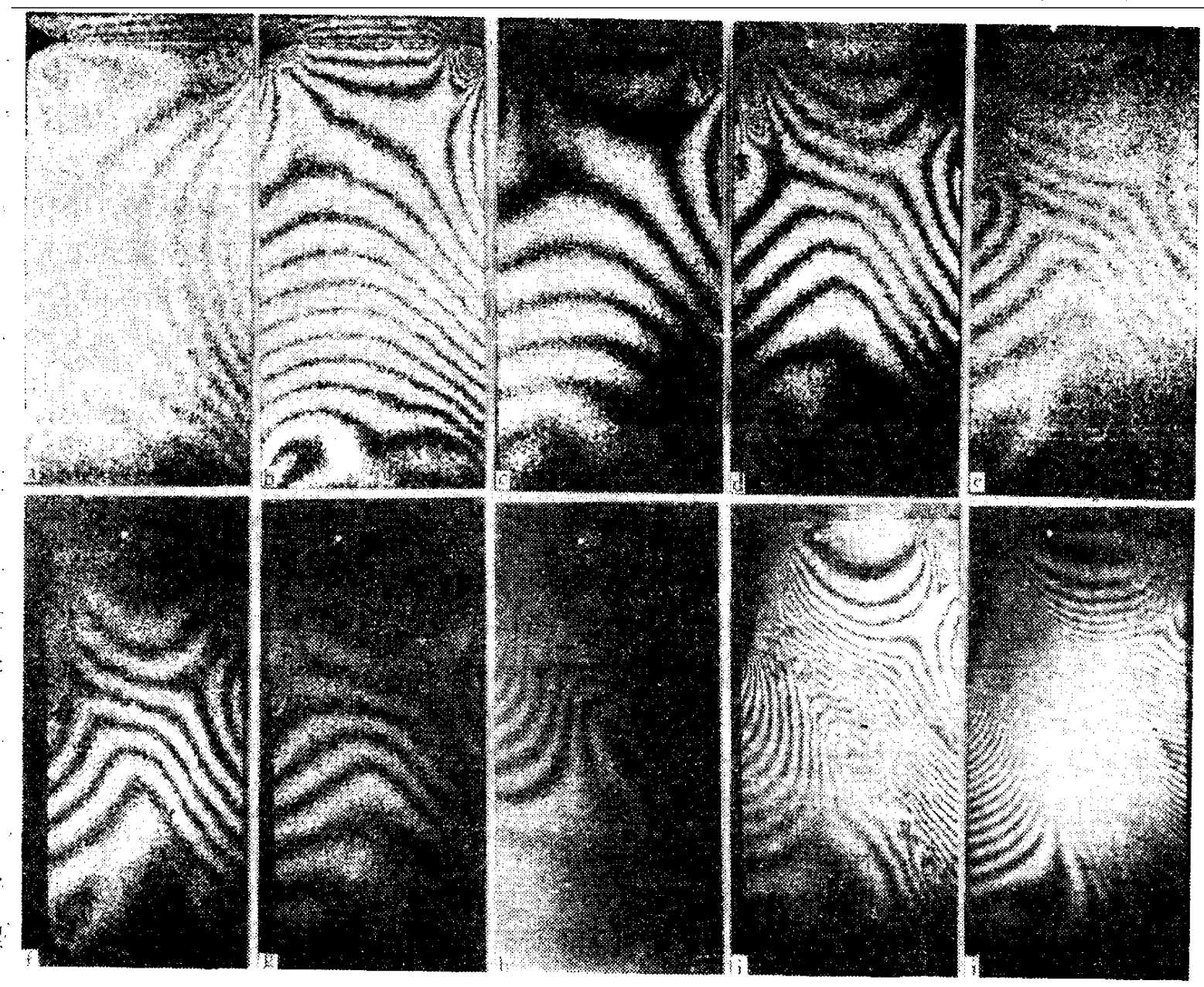

图 2 大理岩破裂过程中表面变形场的干涉条纹照片(单轴压缩) 单位: 吨

(a) $3.00-5.00$; (b) $6.00-8.00$; (c) $9.00-10.00$; (d) $12.00-12.25$;

(e) $12.25-12.50$; (f) $12.50-12.75$; (g) $12.75-13.00$; (h) $13.00-$

$$
13.10 \text {; (i) } 13.10-13.20 \text {; (j) } 13.20-13.30
$$


时, 再进行第二次曝光. 用参考光束照明两次曝光的全息照片, 可以得到反映这两个压力状态 之间岩石位移场的干涉条纹图. 岩石表面的离面位移 $d$ 与干涉条纹级数的关系为:

$$
\begin{gathered}
d=\frac{n \lambda}{2} \quad \text { (对应于亮条纹), } \\
d=(2 n+1) \lambda / 4 \quad \text { (对应于暗条纹). }
\end{gathered}
$$

图 2 是一组用以上方法得到的大理岩表面变形场的全息照片. 图 $2 a-c$ 是岩石试件在应 力为最大主应力的 $70 \%$ 以下拍摄的. 从条纹图上可看到, 在不考虑上下的端部效应时, 岩石 试件的中间部分变形较均匀, 离面位移随压力增加的变化也比较缓慢. 在应力为最大主应力 的 $70 \%-95 \%$ 间拍摄的四张照片如图 $2 \mathrm{~d}-\mathrm{g}$ 所示. 此时岩石试件表面离面位移变化较快, 条纹形成一 “ $\mathrm{X}$ ” 形区域. 随着压力继续增加, 当应力在最大主应力的 $95 \%$ 以上时, 图 $2(\mathrm{~h}) \sim(\mathrm{j})$ 条纹逐渐在一个方向上密集, 表面离面位移变化得很快, 随着压力的增加, 变形集中 区逐渐变窄,最后宏观断裂在该处发生.

上述结果为岩石破裂前变形局部化模式提供了实验依据, 表明激光全息干涉术对岩石力 学研究具有很大潜力.

\section{参考文献}

[1] Spetzler, H. et al., Pure Appt. Gesphys., 112 (1974),571-581.

[2] Soga, A. et al., J. Geophys. Res., 83 (1978), $4451-4458$.

[3] Sobolev G. A. et al., J. Geophys. Res., 83 (1978), 1775-1784. 